\title{
The Improvement of Cardiac and Endothelial Functions of Xue-Fu-Zhu-Yu Decoction for Patients with Acute Coronary Syndrome: A Meta-Analysis of Randomized Controlled Trials
}

\author{
Shiqi Chen $\mathbb{D}^{1},{ }^{1,2}$ Xiaoxiao Wu, ${ }^{2}$ Tong Li, ${ }^{2}$ Weiting Cheng, ${ }^{2}$ Xiaowan Han, ${ }^{1}$ Yang Li, \\ Baofu Wang, ${ }^{1,2}$ Yu Teng, ${ }^{2}$ Mingjing Zhao $\mathbb{D}^{2}$, and Yahong Wang $\mathbb{D}^{1}$ \\ ${ }^{1}$ Department of Cardiology, Dongzhimen Hospital Affiliated to Beijing University of Chinese Medicine, Beijing 100700, China \\ ${ }^{2}$ Key Laboratory of Chinese Medicine of Ministry of Education and Beijing, \\ Dongzhimen Hospital Affiliated to Beijing University of Chinese Medicine, Beijing 100700, China
}

Correspondence should be addressed to Mingjing Zhao; mjgx2004@163.com and Yahong Wang; wyh411@hotmail.com

Received 11 November 2021; Revised 4 January 2022; Accepted 17 January 2022; Published 10 February 2022

Academic Editor: Arquimedes Gasparotto Junior

Copyright (c) 2022 Shiqi Chen et al. This is an open access article distributed under the Creative Commons Attribution License, which permits unrestricted use, distribution, and reproduction in any medium, provided the original work is properly cited.

Background. Xue-Fu-Zhu-Yu decoction (XFZYD) is a traditional Chinese prescription that has been used to treat patients with blood stasis in China for many years. The present study aimed to evaluate the improvement of cardiac and endothelial functions of XFZYD for patients with acute coronary syndrome (ACS) through a systematic review and meta-analysis. Methods. Six databases were searched to collect RCTs related to the treatment of XFZYD for ACS. The primary outcomes were cardiac and endothelial functions, including the levels of left ventricular ejection fraction (LVEF), left ventricular end-diastolic diameter (LVEDD), and left ventricular end-systolic diameter (LVESD) in echocardiography, as well as the changes in the levels of nitric oxide (NO), endothelin-1 (ET-1), intercellular adhesion molecule-1 (ICAM-1), and vascular cell adhesion molecule-1 (VCAM-1) in the serum. The secondary outcomes were the blood levels of oxidative damage markers (including superoxide dismutase (SOD) and malondialdehyde (MDA)), C-reactive protein (CRP), brain natriuretic peptide (BNP), creatine kinase-MB (CK-MB), and cardiac troponin I (cTnI) as well as the incidence of adverse drug reactions (ADRs). Weighted mean difference (WMD) was estimated for all the outcomes with the random effects model. This type of analysis was conducted in the subgroups of the ACS subtypes, and the methodological quality was assessed using the handbook of Cochrane Collaboration. Results. A total of 1,658 records were identified, and 16 randomized controlled trials (1,171 patients) were included. The primary outcomes suggested that XFZYD combined with routine treatment improved LVEF, reduced LVEDD and LVESD, and also improved the serum levels of NO, and reduced the levels of ET-1 and ICAM-1. XFZYD combination therapy significantly ameliorated the blood levels of SOD, MDA, BNP, CK-MB, and cTnI. However, the results indicated no significant difference between XFZYD plus routine treatment and routine treatment for the levels of VCAM-1 and CRP. Moreover, all the ADRs reported in the included studies were slight and the patients recovered soon. Conclusions. The present study suggested that XFZYD may improve the cardiac and endothelial functions of ACS patients without serious ADRs. However, based on the mediocre methodological quality, the aforementioned conclusion should be confirmed in a multicenter, large-scale, and accurately designed clinical trial.

\section{Introduction}

Coronary heart disease (CHD) has been a leading cause of the incidence and mortality worldwide, and it can be divided into acute coronary diseases and stable angina pectoris $[1,2]$. Acute coronary syndrome (ACS), which contains three conditions, including ST-elevation myocardial infarction
(STEMI), non-ST-elevation myocardial infarction (NSTEMI), and unstable angina (UA), can obstruct the balance of myocardial oxygen supply and demand and result in myocardial ischemia [3]. Untreated UA (without serologic elevation of troponin or creatine kinase-MB (CK-MB) isoenzyme concentration) may dynamically progress to myocardial infarction (MI); both NSTEMI and STEMI, 
which can be distinguished by the ST-segment elevation in the electrocardiogram (ECG), exhibit serological evidence of myonecrosis [3]. ACS is mainly caused by the rupture of vulnerable atherosclerotic coronary plaques or the acute formation of the thrombus. Arterial thrombosis due to superficial erosion can activate the endothelium leading to endothelial apoptosis and detachment and induce inflammation and oxidative stress, which affects endothelial dysfunction and platelet aggregation $[4,5]$. Transient or longterm myocardial ischemia also results in impaired cardiac function. Recent studies have shown that the western therapies for ACS are related to inhibition of angina, platelet aggregation, and thrombosis, lowering of cholesterol levels by statin medications, as well as percutaneous coronary intervention (PCI) surgery $[3,6]$. However, these therapies may be inappropriate for certain individuals and can produce specific adverse drug reactions (ADRs) [7-9]. Traditional Chinese medicine (TCM) plays a more extensive therapeutic role in patients who do not undergo PCI surgery and improve the functions of the heart and blood vessels. Under these circumstances, remedies of complementary and alternative medicine are used so as to enhance the therapeutic effect and reduce adverse reaction-associated toxicity.

Xue-Fu-Zhu-Yu decoction (XFZYD) is a well-known TCM formula, which was originally founded by the famous TCM doctor Qingren Wang from the Qing dynasty. XFZYD consists of the following 11 Chinese herbs: Angelicae sinensis (Oliv.), Diels (Danggui), Rehmannia glutinosa Libosch. (Dihuang), Prunus persica (L.) Batsch (Taoren), Carthamus tinctorius L. (Honghua), Glycyrrhiza uralensis Fisch. (Gancao), Aurantii Fructus (Zhiqiao), Paeonia lactiflora Pall. (Chishao), Bupleurum chinense DC. (Chaihu), Ligusticumi chuanxiong Hort. (Chuanxiong), Platycodon grandiflorum (Jacq.) A. DC. (Jiegeng), and Achyranthes bidentata Bl. (Niuxi). The decoction contains at least 34 major constituents including 21 flavonoids, 5 terpenoids, 3 organic acids, 2 lactones, 1 alkaloid, 1 amino acid, and 1 cyanogenic glycoside, which play important roles in the prevention of various cardiovascular diseases [10]. XFZYD has been identified to treat UA patients with blood stasis and Qi stagnation symptoms $[11,12]$, and a variety of its dosage forms have also been approved by the National Medical Products Administration of the Chinese government for clinical practice. Previous studies [13-15] have shown that the integration of XFZYD and Western medicines can improve the angina symptoms and the blood levels of lipids in patients with CHD. However, the amelioration of the cardiac and endothelial functions due to the combination of XFZYD with routine treatment (RT) in ACS has not been fully explored. The indicators detecting these functions are objective in nature and the results are beneficial to assess the authentic efficacy of XFZYD. Considering that a number of clinical trials have examined the use of XFZYD to treat ACS in recent years, we sought to evaluate its efficacy in improving cardiac and endothelial functions through a systematic review and meta-analysis.

\section{Materials and Methods}

This review protocol was registered on PROSPERO (CRD 42021253651).

\subsection{Criteria for considering the Studies in This Review}

2.1.1. Types of Studies. Randomized controlled trials (RCTs) with no limit of publishing language were included.

2.1.2. Types of Participants. The patients that were identified according to accurate ACS diagnostic criteria, which were similar to previously published guidelines $[16,17]$, were eligible for inclusion in this study. According to the International Classification of Diseases 10th revision (ICD-10) codes, the patients with STEMI, NSTEMI, or UA with or without PCI could be included in the present study $[1,18]$.

2.1.3. Types of Interventions in the Experimental and Control Groups. The intervention in the experimental group included XFZYD without addition or subtraction of any herbs and should be combined with the routine treatment (RT) of the control group. The intervention in the control group was the conventional therapy without any other traditional Chinese medicines. RT should be the regular medications of inhibition of angina, platelet aggregation, thrombosis, arrhythmia, hypertension, and diabetes as well as statins according to the guidelines $[3,6]$.

2.1.4. Types of Outcome Measures. The primary outcomes were defined as measures of cardiac and endothelial functions. The levels of left ventricular ejection fraction (LVEF), left ventricular end-diastolic diameter (LVEDD), and left ventricular end-systolic diameter (LVESD) in the echocardiography measurement were used to identify the cardiac function, and the changes in the levels of nitric oxide (NO), endothelin-1 (ET-1), intercellular adhesion molecule-1 (ICAM-1), and vascular cell adhesion molecule-1 (VCAM1) in the serum were representative of the endothelial function. The additional outcomes observed included the blood levels of the oxidative damage markers (superoxide dismutase (SOD) and malondialdehyde (MDA)), C-reactive protein (CRP), brain natriuretic peptide (BNP), and the myocardial enzymes (CK-MB and cardiac troponin I (cTnI)) and ADRs.

2.2. Information Sources and Search Strategy. The search was applied to the following six databases: Cochrane Library, PubMed, Web of Science, the Chinese National Knowledge Infrastructure (CNKI), Wanfang Database, and Weipu Database (VIP), from the inception of each electronic database to February 15, 2021. Additional identification was conducted for all eligible trials by other searching methods from websites and citations. The following terms were used as the mesh terms or the free terms: "acute coronary syndrome," "ACS," "myocardial infarction," "MI," "ST-segment elevation myocardial infarction," "STEMI," "non-ST-segment elevation myocardial infarction," "NSTEMI," "unstable angina," "UA," "unstable angina pectoris," "UAP," "Xuefuzhuyu," "xue-fuzhu-yu," "xuefuzhuyu," and "xue fu zhuyu." The searching strategy in PubMed was performed as ("acute coronary syndrome" [MeSH Terms] OR "acute coronary 
syndrome"[All Fields] OR "ACS"[All Fields] OR "myocardial infarction" [MeSH Terms] OR "myocardial infarction"[All Fields] OR "ST elevation myocardial infarction" [MeSH Terms] OR "ST elevation myocardial infarction"[All Fields] OR "ST segment elevation myocardial infarction"[All Fields] OR "STEMI"[All Fields] OR "non ST elevated myocardial infarction" [MeSH Terms] OR "non ST elevated myocardial infarction"[All Fields] OR "NSTEMI"[All Fields] OR "angina, unstable" [MeSH Terms] OR ("angina”[All Fields] AND "unstable"[All Fields]) OR "unstable angina"[All Fields] OR ("unstable"[All Fields] AND "angina"[All Fields] AND "pectoris"[All Fields]) OR "unstable angina pectoris"[All Fields] OR "UAP”[All Fields] OR "UA"[All Fields]) AND ("Xuefuzhuyu"[All Fields] OR "xue-fu-zhu-yu"[All Fields] OR "xue fu zhu yu"[All Fields] OR "xuefu zhuyu”[All Fields]).

2.3. Study Selection. Two investigators (SQC and TL) independently carried out a literature search using the predetermined criteria in the NoteExpress 3.2 software. Initially, duplications were found in all databases and removed from the original search results. Furthermore, the apparently irrelevant studies were excluded following the reading of the titles and abstracts. Finally, the full texts were screened to identify the related studies, and the unqualified studies were excluded. The process of study selection was cross-checked by two researchers. Any disagreement was discussed and resolved in a consensus meeting with the corresponding author (YHW and MJZ).

2.4. Data Extraction. After the selection, two authors (XXW and WTC) independently extracted data from the included studies by using a standardized sheet, which was prepared for this review. The extracted data included the study title, name of the first author, year of publication, the diagnostic criteria of the patients, age of participants, baseline, disease types, sample size, interventions in the treatment and control groups, treatment duration, treatment dose, and outcome measures.

2.5. Risk of Bias in Individual Studies. Two authors (XWH and YL) independently assessed the risk of bias using assessment tools provided by the handbook of Cochrane Collaboration to evaluate the methodological quality of included studies, involving the blinding of outcomes assessment (i.e., detection bias), the blinding of participants and personnel (i.e., performance bias), the random sequence generation (i.e., selection bias), the allocation concealment (i.e., selection bias), the incomplete outcomes data (i.e., attrition bias), the selective reporting (i.e., reporting bias), and other biases. Disagreements were resolved by consensus with the corresponding author (YHW and MJZ).

\subsection{Strategy for Data Synthesis}

2.6.1. Statistical Analysis. Review Manager 5.3 software provided by the Cochrane Collaboration was used to conduct data analysis. Dichotomous data were calculated as the risk ratios (RR) and the 95\% confidence interval (CI). Continuous outcomes were expressed as weighted mean difference (WMD) or standardized mean difference (SMD) with $95 \%$ CI. SMD would be applied in preference if the included studies used different units or rating instruments [19]. $P<0.05$ was considered to indicate a statistically significant difference.

2.6.2. Assessment of Heterogeneity. The heterogeneity of the included studies was analyzed with the $\chi^{2}$ test. When $I^{2} \leq 50 \%$, a small heterogeneity was considered among the studies, and the fixed effects model was used for data analysis. In case the statistical heterogeneity was $I^{2}>50 \%$, the sources of heterogeneity were measured. Subgroup analysis was performed in the presence of clinical heterogeneity, such as the subtypes of ACS, including STEMI, NSTEMI, and UA. In case of significant heterogeneity, the random effects model was considered, or only the descriptive analysis was performed.

2.6.3. Sensitivity Analysis. The studies with high weight and low quality were excluded. Following the comparison of the pooled statistics prior to and following exclusion of these studies, certain differences could be found. Subgroup and sensitivity analyses were also conducted to explore the stability of the results if necessary.

\section{Results}

3.1. Study Selection. A total of 1,658 articles were retrieved from six literature databases. Following the removal of 722 duplicates, 936 potentially relevant articles remained for subsequent assessment. Following evaluation of titles and abstracts, 830 articles were excluded. A total of 90 out of 106 remaining studies were excluded following the investigation of the full texts. Finally, 16 studies [20-35] were included in the meta-analysis. A flow chart (Figure 1) indicated the search process and study selection.

3.2. Study Characteristics. A total of 1,658 records were identified and 16 RCTs [20-35] were included, covering 1,171 participants. All the studies were conducted in China and almost all of them were published in Chinese. Only one was published in English. They were published from 2004 to 2020. The sample size varied from 49 to 104 subjects, and the duration of the XFZYD treatment ranged from 1 to 12 weeks. The disease diagnoses of these studies were AMI, STEMI, UNSTEMI, and UA with or without PCI. Further details regarding the characteristics of the included studies are shown in Table 1 and supplementary Table S1.

3.3. Risk of Bias and Methodological Quality. According to the assessment tools provided by the handbook of Cochrane Collaboration, the included studies displayed methodological bias (Figure 2). All the included studies were described as "randomized" studies; among them, five studies reported 


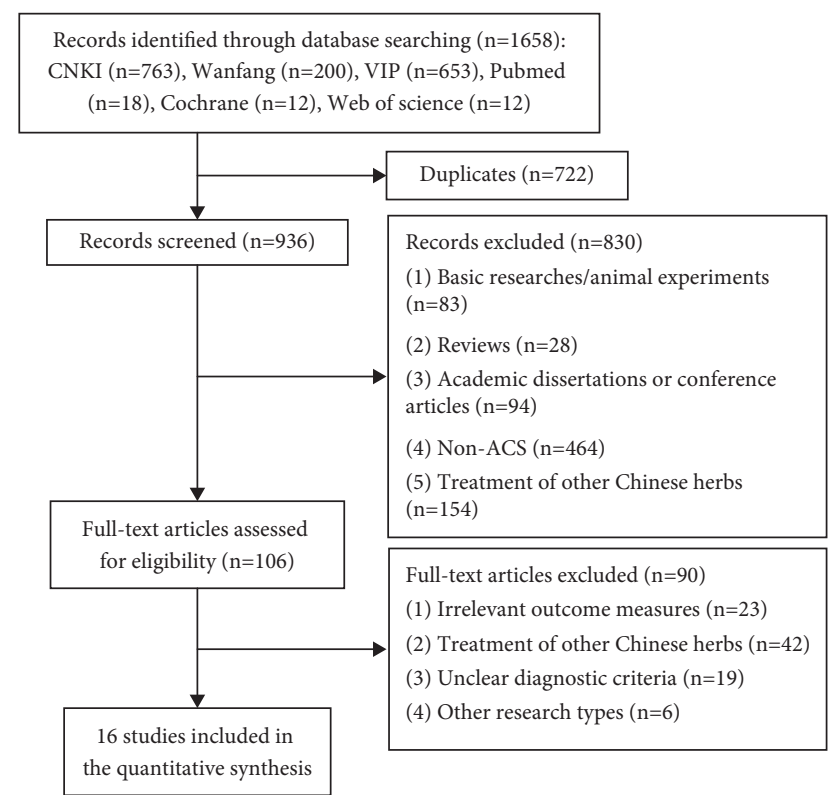

FIGURE 1: Flow chart for searching and screening of the studies.

using the "random number table" [21, 26, 27, 29, 31], and one study used the toss method [23]. However, the allocation concealment, the blinding of the participants, and the outcome assessment were not clear in any of the studies investigated. The data reported in the results were complete according to the methods used. Therefore, the incomplete outcome data were identified as low risks. Although not all the studies included provided protocols, the expected outcome indicators were reported and the selective reporting bias was defined as low risk. The results indicated that the methodological quality of the 16 literature studies included in this meta-analysis was generally mediocre.

\subsection{Outcome Measures}

3.4.1. Cardiac Functions. In total, six studies [20-23, 25, 35] reported the outcome of LVEF from the ECG. Three studies [20, 22, 25] included AMI patients with PCI, one study [21] included only UA patients, one study [35] included AMI patients, and one study [23] explicitly included STEMI patients with PCI. Subgroup meta-analysis was performed due to the high total heterogeneity $\left(I^{2}=62 \%\right)$, and the random effects model was used in the meta-analysis. As shown in Figure 3, the combination of XFZYD with RT therapy performed better in improving LVEF (MD 6.35, 95\% CI 4.20 to $\left.8.50 ; P<0.00001 ; I^{2}=62 \%\right)$. Therefore, it could be used to maintain the cardiac function, and the heterogeneity among AMI with the PCI subgroup was reduced to $0 \%$.

LVEDD and LVESD were also collected from the echocardiography data and were used to indicate cardiac functions. Among the included studies, five studies [20, 21, 23, 25, 35] reported LVEDD and three [23, 25, 35] reported LVESD. As shown in Figure 4, five studies demonstrated a high heterogeneity $\left(I^{2}=98 \%\right)$, and the subgroup meta-analysis was applied to identify the AMI patients with
PCI [20, 25], the STEMI patients with PCI [23], the UA patients [21], and the AMI patients [35]. The results indicated that the combination of XFZYD with RT therapy could decrease LVEDD (MD -3.48, 95\% CI -5.68 to -1.29 ; $\left.P=0.002 ; I^{2}=98 \%\right)$. The subgroup of AMI patients with PCI reduced the heterogeneity to $38 \%$ and resulted in a positive result. Following analysis of LVESD, the three studies included AMI patients with PCI [25], STEMI patients with PCI [23], and AMI patients [35], respectively. Therefore, they were not merged in the meta-analysis. Each of the three studies indicated a significant difference in improving LVESD following comparison of XFZYD plus RT with RT $(26.19 \pm 0.87$ vs. $29.03 \pm 2.05 ; \quad 32.4 \pm 3.3$ vs. $39.5 \pm 3.4$; $27.96 \pm 1.56$ vs. $29.28 \pm 1.38)$.

3.4.2. The Endothelial Functions. In total, four studies $[25,27,31,34]$ reported the serum levels of NO, and three of them included UA patients [27, 31, 34]. One study included AMI patients with PCI [25]. A meta-analysis with a random effects model was conducted in all four studies. The results indicated that the serum levels of NO were significantly increased following the comparison of XFZYD plus RT with RT (MD 12.57, 95\% CI 2.95 to $22.19 ; P=0.01 ; I^{2}=95 \%$ ). However, the heterogeneity was high and the subgroups were performed in the meta-analysis so as to reduce the heterogeneity to $0 \%$ as shown in Figure 5.

The serum levels of ET-1 were also related to the endothelial functions, and a total of five studies $[25,27,29,31,34]$ reported this index. As shown in Figure 6, a meta-analysis in the random effects model was performed in the five studies. XFZYD plus RT significantly reduced the serum levels of ET-1 compared with those noted for RT (MD $-30.93,95 \% \mathrm{CI}-56.59$ to $\left.-5.27 ; P=0.02 ; I^{2}=99 \%\right)$. In the subgroup meta-analysis, the heterogeneity was still high $\left(I^{2}=85 \%\right)$ in the UA group $[27,31,34]$ and the outcome was also stable.

In total, three studies $[26,31,34]$ related to UA patients reported measurement of ICAM-1 and VCAM-1 levels in the serum. These studies were applied in the meta-analysis. The results are shown in Figures 7 and 8. XFZYD plus RT significantly reduced the serum levels of ICAM-1 compared with those of RT alone (MD $-50.42,95 \%$ CI -92.36 to -8.48 ; $P=0.02 ; I^{2}=97 \%$, while XFZYD plus RT did not significantly lower the serum levels of VCAM-1 compared with those of RT alone (MD -41.07, 95\% CI -94.39 to 12.25 ; $\left.P=0.13 ; I^{2}=98 \%\right)$.

3.4.3. Assessment of CRP and Oxidative Damage Marker Levels. Three studies $[30,32,33]$ reported the serum levels of $\mathrm{CRP}$, and three studies $[22,23,25]$ reported the determination of both SOD and MDA serum levels. One of the studies [32] indicated that XFZYD plus RT increased the serum levels of CRP compared with those of RT alone (30.88 \pm 0.93 vs. $30.1 \pm 0.86)$, which was opposite to the other two studies $(3.21 \pm 2.74$ vs. $8.12 \pm 4.39 ; 4.34 \pm 0.95$ vs. $4.91 \pm 1.03)[30,33]$. In a meta-analysis (Figure 9), the levels of CRP exhibited no significant difference following comparison of XFZYD plus RT with RT (MD -1.35, 95\% CI 
TABLE 1: Characteristics of the included studies.

\begin{tabular}{|c|c|c|c|c|c|c|c|c|}
\hline \multirow[b]{2}{*}{ Study ID } & \multirow{2}{*}{$\begin{array}{c}\text { Sample } \\
\text { size (T/ } \\
\text { C) }\end{array}$} & \multirow[b]{2}{*}{ Type of disease } & \multirow[b]{2}{*}{ Age $(\mathrm{T} / \mathrm{C})$} & \multirow[b]{2}{*}{ Baseline } & \multicolumn{2}{|c|}{ Interventions } & \multirow[b]{2}{*}{ Duration } & \multirow[b]{2}{*}{ Outcome measures } \\
\hline & & & & & Treatment group & $\begin{array}{l}\text { Control } \\
\text { group }\end{array}$ & & \\
\hline $\begin{array}{l}\text { Lu (2020) } \\
{[21]}\end{array}$ & $43 / 40$ & UA & $\begin{array}{c}62.57 \pm 8.42 / \\
63.39 \pm 8.90\end{array}$ & $\mathrm{C}$ & XFZYD + amiodarone & Amiodarone & $4 w$ & (1) (2) (11) \\
\hline $\begin{array}{l}\mathrm{Zu}(2020) \\
{[20]}\end{array}$ & $38 / 38$ & $\mathrm{AMI}+\mathrm{PCI}$ & $\begin{array}{c}59.68 \pm 8.46 / \\
60.16 \pm 8.26\end{array}$ & $\mathrm{C}$ & XFZYD + RT & RT & $8 w$ & (1) (2) \\
\hline $\begin{array}{l}\mathrm{Li}(2019) \\
{[23]}\end{array}$ & $46 / 45$ & STEMI + PCI & $\begin{array}{c}59.03 \pm 3.62 / \\
58.19 \pm 3.86\end{array}$ & $\mathrm{C}$ & $\mathrm{XFZYD}+\mathrm{RT}$ & RT & $1 \mathrm{w}$ & (1) (2) (3) (9) (10) (12) \\
\hline $\begin{array}{l}\text { Wen } \\
(2019) \\
{[22]}\end{array}$ & $52 / 52$ & $\mathrm{AMI}+\mathrm{PCI}$ & $\begin{array}{c}60.30 \pm 4.85 / \\
60.25 \pm 4.87\end{array}$ & $\mathrm{C}$ & XFZYD + RT & RT & $4 w$ & (1) (9) (10) (12) \\
\hline $\begin{array}{l}\text { Liu and } \\
\text { Liu (2018) } \\
{[24]}\end{array}$ & $40 / 40$ & UA & NA/NA & $\mathrm{C}$ & XFZYD + RT & RT & $4 w$ & (14) \\
\hline $\begin{array}{l}\mathrm{Li}(2017) \\
{[26]}\end{array}$ & $30 / 30$ & UA & $\begin{array}{c}57.9 \pm 8.3 / \\
58.2 \pm 8.5\end{array}$ & $\mathrm{C}$ & XFZYD + RT & RT & $2 \mathrm{w}$ & (6) (7) (12) (13) (14) \\
\hline $\begin{array}{l}\text { Wang } \\
(2017) \\
{[25]}\end{array}$ & $53 / 53$ & $\mathrm{AMI}+\mathrm{PCI}$ & $\begin{array}{c}57.36 \pm 8.24 / \\
59.02 \pm 9.78\end{array}$ & $\mathrm{C}$ & XFZYD + RT & RT & $2 w$ & (1) (2) (3) (4) (5) (9) (10) (12) \\
\hline $\begin{array}{l}\text { Wang } \\
(2016) \\
{[27]}\end{array}$ & $34 / 34$ & UA & NA/NA & $\mathrm{C}$ & XFZYD + RT & RT & $8 w$ & (4) (5) \\
\hline $\begin{array}{l}\text { Liu et al. } \\
(2013) \\
{[28]}\end{array}$ & $30 / 30$ & AMI & NA/NA & $\mathrm{C}$ & XFZYD + RT & RT & $2 w$ & (11) \\
\hline $\begin{array}{l}\text { Zhang } \\
\text { et al. } \\
(2012) \\
{[29]}\end{array}$ & $30 / 30$ & AMI & $61 \pm 7 / 59 \pm 8$ & $\mathrm{C}$ & XFZYD + RT & RT & $2 \mathrm{w}$ & (5) \\
\hline $\begin{array}{l}\text { Jiang } \\
(2011) \\
{[30]}\end{array}$ & $40 / 40$ & UA & NA/NA & $\mathrm{C}$ & XFZYD + RT & RT & $4 \mathrm{w}$ & (8) \\
\hline $\begin{array}{l}\text { Guo } \\
(2009) \\
\text { [32] } \\
\text { Zheng and }\end{array}$ & $25 / 24$ & UA & NA/NA & $\mathrm{C}$ & XFZYD + RT & RT & $2 w$ & (8) (11) \\
\hline $\begin{array}{l}\text { Wang } \\
(2009) \\
{[31]}\end{array}$ & $30 / 30$ & UA & $\begin{array}{c}64.8 \pm 7.9 / \\
65.2 \pm 7.4\end{array}$ & $\mathrm{C}$ & XFZYD + RT & RT & $8 w$ & (4) (5) (6) (7) \\
\hline $\begin{array}{l}\text { Chen et al. } \\
\text { (2008) } \\
{[33]}\end{array}$ & $42 / 42$ & USTEMI + UA & $\begin{array}{c}62.83 \pm 10.14 / \\
64.83 \pm 10.75\end{array}$ & $\mathrm{C}$ & XFZYD + RT & RT & $8 w$ & (8) \\
\hline $\begin{array}{l}\text { Wang } \\
\text { et al. } \\
(2006) \\
{[34]}\end{array}$ & $32 / 18$ & UA & $\begin{array}{c}65.4 \pm 7.6 / \\
65.3 \pm 7.8\end{array}$ & $\mathrm{C}$ & $\mathrm{XFZYD}+\mathrm{RT}$ & RT & $8 w$ & (4) (5) (6) (7) \\
\hline $\begin{array}{l}\text { Tang et al. } \\
(2004) \\
{[35]}\end{array}$ & $30 / 30$ & AMI & NA/NA & $\mathrm{C}$ & XFZYD + RT & RT & $12 w$ & (1) (2) (3) \\
\hline
\end{tabular}

(1) LVEF; (2) LVEDD; (3) LVESD; (4) NO; (5) ET-1; (6) ICAM-1; (7) VCAM-1; (8) CRP; (9) SOD; (10) MDA; (11) BNP; (12) CK-MB; (13) cTnI; (14) ADRs. The numerical values of age are presented as mean value \pm standard deviation in the treatment group $(\mathrm{T})$ and the control group (C). Abbreviations: ADRs, adverse drug reactions; AMI, actue myocardial infarction; BNP, brain natriuretic peptide; C, consistent; CK-MB, creatine kinase-MB; CRP, C-reactive protein; cTnI, cardiac troponin I; ET-1, endothelin-1; ICAM-1, intercellular adhesion molecule-1; LVEF, left ventricular ejection fraction; LVEDD, left ventricular enddiastolic diameter; LVESD, left ventricular end-systolic diameter; MDA, malondialdehyde; NA, not available; NO, nitric oxide; NSTEMI, non-ST-segment elevation myocardial infarction; PCI, percutaneous coronary intervention; RT, routine treatment; SOD, superoxide dismutase; STEMI, ST-segment elevation myocardial infarction; T/C, treatment group/control group; UA, unstable angina; VCAM-1, vascular cell adhesion molecule-1; w, week; XFZYD, Xue-FuZhu-Yu decoction.

-3.24 to $\left.0.53 ; P=0.16 ; I^{2}=96 \%\right)$. Moreover, a meta-analysis was conducted to assess the changes in the levels of SOD and MDA (Figures 10 and 11). The results indicated that XFZYD plus RT caused a significant increase in SOD levels (MD $19.31,95 \%$ CI 15.96 to 22.66; $P<0.00001 ; I^{2}=0 \%$ ), and they also decreased MDA levels (MD -1.61, 95\% CI -1.90 to 


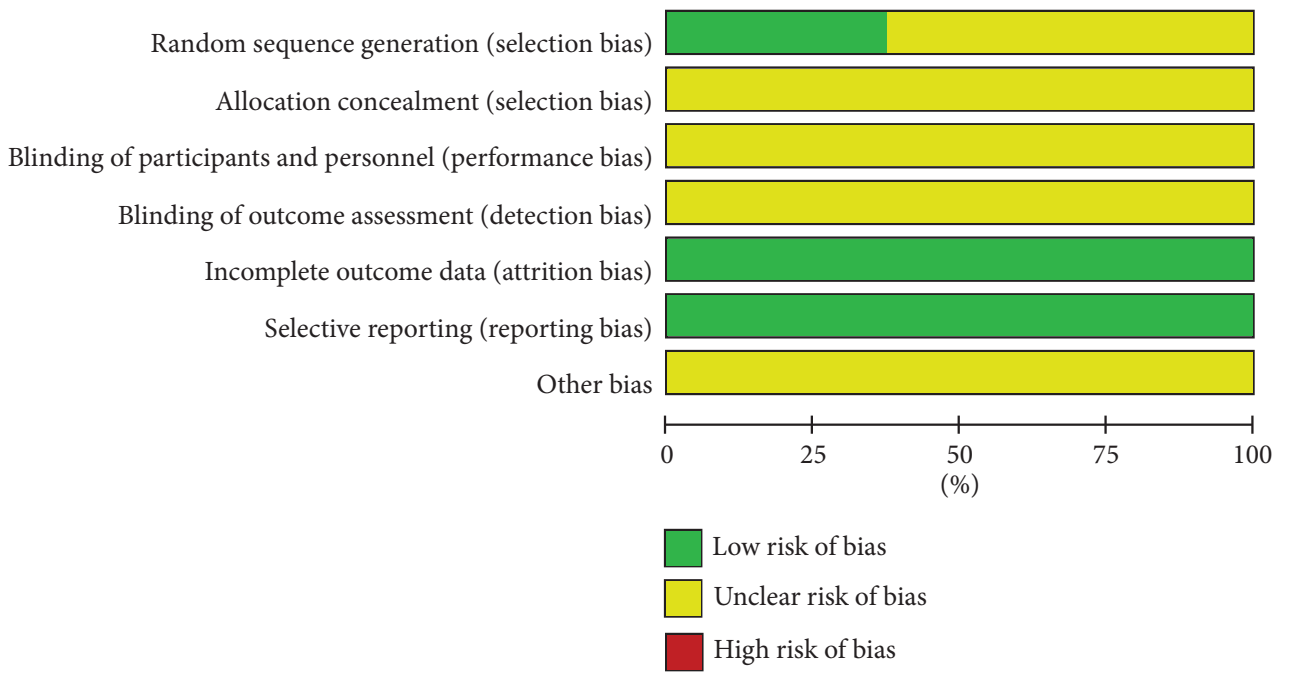

Figure 2: Risk of bias graph.

\begin{tabular}{|c|c|c|c|c|c|c|c|c|c|c|}
\hline \multirow{3}{*}{$\begin{array}{l}\text { Study or Subgroup } \\
1.1 .1 \mathrm{AMI}+\mathrm{PCI}\end{array}$} & \multicolumn{3}{|c|}{ Experimental } & \multicolumn{3}{|c|}{ Control } & \multirow{2}{*}{$\begin{array}{l}\text { Weight } \\
(\%)\end{array}$} & \multirow{2}{*}{$\begin{array}{l}\text { Mean Difference } \\
\text { IV, Random, 95\% CI }\end{array}$} & \multirow{2}{*}{\multicolumn{2}{|c|}{$\begin{array}{l}\text { Mean Difference } \\
\text { IV, Random, 95\% CI }\end{array}$}} \\
\hline & Mean & SD & Total & Mean & SD & Total & & & & \\
\hline & & & & & & & & & & \\
\hline Wang 2017 & 70.21 & 8.32 & 53 & 65.49 & 7.91 & 53 & 17.5 & $4.72[1.63,7.81]$ & & $-1-$ \\
\hline Wen 2019 & 70.36 & 7.14 & 52 & 65.26 & 5.47 & 52 & 20.2 & $5.10[2.66,7.54]$ & & - \\
\hline $\mathrm{Zu} 2020$ & 70.26 & 7.95 & 38 & 65.37 & 6.87 & 38 & 16.5 & $4.89[1.55,8.23]$ & & -1 \\
\hline Subtotal (95\% CI) & & & 143 & & & 143 & 54.3 & $4.94[3.28,6.60]$ & & 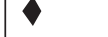 \\
\hline \multicolumn{11}{|c|}{ Heterogeneity: $\mathrm{Tau}^{2}=0.00 ; \mathrm{Chi}^{2}=0.04, \mathrm{df}=2(P=0.98) ; I^{2}=0 \%$} \\
\hline \multicolumn{11}{|c|}{ Test for overall effect: $Z=5.82(P<0.00001)$} \\
\hline \multicolumn{11}{|l|}{ 1.1.2 STEMI+PCI } \\
\hline Li 2019 & 71.03 & 9.36 & 46 & 65.24 & 5.19 & 45 & 17.5 & $5.79[2.69,8.89]$ & & \\
\hline Subtotal (95\% CI) & & & 46 & & & 45 & 17.5 & $5.79[2.69,8.89]$ & & \\
\hline \multicolumn{11}{|c|}{$\begin{array}{l}\text { Heterogeneity: Not applicable } \\
\text { Test for overall effect: } Z=3.66(P=0.0003)\end{array}$} \\
\hline \multicolumn{11}{|l|}{ 1.1.3 UA } \\
\hline Lu 2020 & 49.72 & 7.65 & 43 & 43.68 & 8.26 & 40 & 16.1 & $6.04[2.61,9.47]$ & & \\
\hline Subtotal (95\% CI) & & & 43 & & & 40 & 16.1 & $6.04[2.61,9.47]$ & & \\
\hline \multicolumn{11}{|c|}{ Heterogeneity: Not applicable } \\
\hline \multicolumn{11}{|c|}{ Test for overall effect: $Z=3.45(P=0.0006)$} \\
\hline \multicolumn{11}{|l|}{ 1.1.4 AMI } \\
\hline Tang et al. 2004 & 56.1 & 10.1 & 30 & 42.1 & 8 & 30 & 12.1 & $14.00[9.39,18.61]$ & & \\
\hline Subtotal (95\% CI) & & & 30 & & & 30 & 12.1 & $14.00[9.39,18.61]$ & & \\
\hline \multicolumn{11}{|c|}{ Heterogeneity: Not applicable } \\
\hline \multicolumn{11}{|c|}{ Test for overall effect: $Z=5.95(P<0.00001)$} \\
\hline Total $(95 \%$ CI) & & & 262 & & & 258 & 100.0 & $6.35[4.20,8.50]$ & & \\
\hline \multicolumn{9}{|c|}{ Heterogeneity: $\mathrm{Tau}^{2}=4.39 ; \mathrm{Chi}^{2}=13.18, \mathrm{df}=5(P=0.02) ; I^{2}=62 \%$} & $-20-10$ & $\begin{array}{ll}1 \\
0 & 10\end{array}$ \\
\hline \multicolumn{6}{|c|}{ Test for overall effect: $Z=5.79(\mathrm{P}<0.00001)$} & & & & Favours (control) & Favours \\
\hline
\end{tabular}

FIGURE 3: The LVEF of the included studies.

$\left.-1.33 ; P<0.00001 ; I^{2}=0 \%\right)$ compared with the effects noted following treatment with RT alone. The heterogeneity noted was very low.

3.4.4. The Blood Levels of BNP. Three studies [21, 28, 32] reported the blood levels of BNP. As shown in Figure 12, the levels of BNP were significantly different compared with those of RT alone (MD $-49.43,95 \%$ CI -71.18 to -27.68 ; $\left.P<0.00001 ; I^{2}=99 \%\right)$. The subgroups were performed due to the high heterogeneity, and the heterogeneity of the UA group $[21,32]$ was reduced to $78 \%$.

3.4.5. Myocardial Enzymes. In total, four studies $[22,23,25,26]$ reported the assessment of CK-MB as a 


\begin{tabular}{|c|c|c|c|c|c|c|c|c|c|c|c|c|}
\hline \multirow{3}{*}{$\begin{array}{l}\text { Study or Subgroup } \\
1.2 .1 \mathrm{AMI}+\mathrm{PCI}\end{array}$} & \multicolumn{3}{|c|}{ Experimental } & \multicolumn{3}{|c|}{ Control } & \multirow{2}{*}{$\begin{array}{l}\text { Weight } \\
(\%)\end{array}$} & \multirow{2}{*}{$\begin{array}{l}\text { Mean Difference } \\
\text { IV, Random, 95\% CI }\end{array}$} & \multirow{2}{*}{\multicolumn{4}{|c|}{$\begin{array}{l}\text { Mean Difference } \\
\text { IV, Random, 95\% CI }\end{array}$}} \\
\hline & Mean & \multirow[t]{2}{*}{$\mathrm{SD}$} & \multirow[t]{2}{*}{ Total } & \multirow[t]{2}{*}{ Mean } & \multirow[t]{2}{*}{$\mathrm{SD}$} & \multirow[t]{2}{*}{ Total } & & & & & & \\
\hline & \multirow{4}{*}{$\begin{array}{l}45.26 \\
45.04\end{array}$} & & & & & & & & & & & \\
\hline Wang 2017 & & 1.08 & 53 & 46.18 & 1.26 & 53 & 21.2 & $-0.92[-1.37,-0.47]$ & & - & & \\
\hline $\mathrm{Zu} 2020$ & & 1.03 & 38 & 46.39 & 1.15 & 38 & 21.2 & $-1.35[-1.84,-0.86]$ & & - & & \\
\hline Subtotal $(95 \%$ CI $)$ & & & 91 & & & 91 & 42.4 & $-1.12[-1.54,-0.70]$ & & $\gamma$ & & \\
\hline Heterogeneity: $\mathrm{Tau}^{2}$ & $h i^{2}=1$ &, $\mathrm{df}=$ & $(P=0$ & 20); $I^{2}=$ & $8 \%$ & & & & & & & \\
\hline Test for overall effect & $3(P<0$. & 0001) & & & & & & & & & & \\
\hline 1.2.2 STEMI+PCI & & & & & & & & & & & & \\
\hline Li 2019 & 40.03 & 0.48 & 46 & 45.02 & 1.25 & 45 & 21.3 & $-4.99[-5.38,-4.60]$ & & 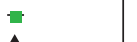 & & \\
\hline Subtotal (95\% CI) & & & 46 & & & 45 & 21.3 & $-4.99[-5.38,-4.60]$ & & $\vartheta$ & & \\
\hline Heterogeneity: Not a & & & & & & & & & & & & \\
\hline Test for overall effect & $03(P<0$ & 00001 & & & & & & & & & & \\
\hline $1.2 .3 \mathrm{UA}$ & & & & & & & & & & & & \\
\hline Lu 2020 & 53.37 & 4.51 & 43 & 56.21 & 5.58 & 40 & 17.6 & $-2.84[-5.03,-0.65]$ & & & & \\
\hline Subtotal (95\% CI) & & & 43 & & & 40 & 17.6 & $-2.84[-5.03,-0.65]$ & & & & \\
\hline Heterogeneity: Not a & & & & & & & & & & & & \\
\hline Test for overall effect & $4(P<0$. & & & & & & & & & & & \\
\hline 1.1.4 AMI & & & & & & & & & & & & \\
\hline Tang et al. 2004 & 47.2 & 3.6 & 30 & 54.9 & 3.5 & 30 & 18.7 & $-7.70[-9.50,-5.90]$ & & & & \\
\hline Subtotal $(95 \%$ CI $)$ & & & 30 & & & 30 & 18.7 & $-7.70[-9.50,-5.90]$ & & & & \\
\hline Heterogeneity: Not a & & & & & & & & & & & & \\
\hline Test for overall effect & $0(P<0$. & 0001) & & & & & & & & & & \\
\hline Total (95\% CI) & & & 210 & & & 206 & 100.0 & $-3.48[-5.68,-1.29]$ & & & & \\
\hline Heterogeneity: Tau $^{2}$ & $\mathrm{hi}^{2}=25$ & $.78, \mathrm{df}$ & $=4(P<$ & $0.00001)$ & $I^{2}=9$ & & & & 1 & & & 1 \\
\hline Test for overall effect & $1(P=0$. & 02) & & & & & & & -10 & 0 & 5 & 10 \\
\hline Test for subgroup di & $\mathrm{Chi}^{2}=$ & 98.02 , & $=3(1$ & $<0.000$ & 1), $I^{2}$ & $98.5 \%$ & & & Favo & perimental) & Favours & \\
\hline
\end{tabular}

FIgURE 4: The LVEDD of the included studies.

\begin{tabular}{|c|c|c|c|c|c|c|c|c|c|c|c|}
\hline \multirow{3}{*}{$\begin{array}{l}\text { Study or Subgroup } \\
2.1 .1 \mathrm{UA}\end{array}$} & \multicolumn{3}{|c|}{ Experimental } & \multicolumn{3}{|c|}{ Control } & \multirow{2}{*}{$\begin{array}{c}\text { Weight } \\
(\%)\end{array}$} & \multirow{2}{*}{$\begin{array}{l}\text { Mean Difference } \\
\text { IV, Random, 95\% CI }\end{array}$} & \multirow{2}{*}{\multicolumn{3}{|c|}{$\begin{array}{c}\text { Mean Difference } \\
\text { IV, Random, 95\% CI }\end{array}$}} \\
\hline & Mean & SD & Total & Mean & $\mathrm{SD}$ & Total & & & & & \\
\hline & & & & & & & & & & & \\
\hline Wang 2016 & 78.36 & 12.81 & 34 & 61.13 & 16.25 & 34 & 23.6 & $17.23[10.27,24.19]$ & & & \\
\hline Wang et al. 2006 & 67.7 & 11.3 & 32 & 52.6 & 8.9 & 18 & 24.6 & $15.10[9.42,20.78]$ & & & \\
\hline Zheng and Wang 2009 & 72.5 & 12.4 & 30 & 55.9 & 8.4 & 30 & 24.9 & $16.60[11.24,21.96]$ & & & \\
\hline Subtotal $(95 \%$ CI $)$ & & & 96 & & & 82 & 73.1 & $16.21[12.81,19.61]$ & & & \\
\hline \multicolumn{12}{|c|}{ Heterogeneity: $\mathrm{Tau}^{2}=0.00 ; \mathrm{Chi}^{2}=0.25, \mathrm{df}=2(P=0.88) ; I^{2}=0 \%$} \\
\hline \multicolumn{12}{|c|}{ Test for overall effect: $Z=9.35(P<0.00001)$} \\
\hline \multicolumn{12}{|l|}{ 2.1.2 $\mathrm{AMI}+\mathrm{PCI}$} \\
\hline Wang 2017 & 8.73 & 1.68 & 53 & 6.29 & 1.75 & 53 & 26.9 & $2.44[1.79,3.09]$ & & $\square$ & \\
\hline Subtotal $(95 \% \mathrm{CI})$ & & & 53 & & & 53 & 26.9 & $2.44[1.79,3.09]$ & & $\boldsymbol{\theta}$ & \\
\hline \multicolumn{12}{|c|}{ Heterogeneity: Not applicable } \\
\hline \multicolumn{12}{|c|}{ Test for overall effect: $Z=7.32(P<0.00001)$} \\
\hline Total (95\% CI) & & & 149 & & & 135 & 100.0 & $12.57[2.95,22.19]$ & & & \\
\hline \multicolumn{9}{|c|}{ Heterogeneity: $\mathrm{Tau}^{2}=89.48 ; \mathrm{Chi}^{2}=61.04, \mathrm{df}=3(P<0.00001) ; I^{2}=95 \%$} & $-20 \quad-10$ & & 20 \\
\hline \multicolumn{9}{|c|}{ Test for overall effect: $Z=2.56(P=0.01)$} & $\begin{array}{ll}-20 & -10 \\
\text { Favours (control) }\end{array}$ & $\begin{array}{lr}0 & 10 \\
\text { Favours }(\mathrm{e}\end{array}$ & $\begin{array}{l}20 \\
\text { imental) }\end{array}$ \\
\hline
\end{tabular}

FIgURE 5: The serum NO levels of the included studies.

cardiac marker, and two of them [22, 25] included AMI patients with PCI, whereas one study [26] included UA patients, and one [23] STEMI patients with PCI. A total of four studies were involved in a meta-analysis (Figure 13). The results indicated that XFZYD plus RT significantly decreased the levels of CK-MB compared with those noted following RT treatment alone (MD - 10.08, 95\% CI - 14.01 to $\left.-6.15 ; P<0.00001 ; I^{2}=96 \%\right)$. Due to the high heterogeneity, the subgroups of AMI plus PCI, UA, and STEMI plus PCI were used. The heterogeneity in the AMI plus PCI subgroup was very low $\left(I^{2}=0 \%\right)$. One study [26] reported on the changes in the levels of cTnI between the XFZYD plus RT 


\begin{tabular}{|c|c|c|c|c|c|c|c|c|c|c|c|c|}
\hline \multirow{3}{*}{$\begin{array}{l}\text { Study or Subgroup } \\
2.2 .1 \mathrm{UA}\end{array}$} & \multicolumn{3}{|c|}{ Experimental } & \multicolumn{3}{|c|}{ Control } & \multirow{2}{*}{$\begin{array}{l}\text { Weight } \\
(\%)\end{array}$} & \multirow{2}{*}{$\begin{array}{c}\text { Mean Difference } \\
\text { IV, Random, 95\% CI }\end{array}$} & \multirow{2}{*}{\multicolumn{4}{|c|}{$\begin{array}{c}\text { Mean Difference } \\
\text { IV, Random, 95\% CI }\end{array}$}} \\
\hline & Mean & SD & Total & Mean & SD & Total & & & & & & \\
\hline & & & & & & & & & & & & \\
\hline Wang 2016 & 62.48 & 19.57 & 34 & 73.64 & 25.49 & 34 & 19.7 & $-11.16[-21.96,-0.36]$ & & & & \\
\hline Wang et al. 2006 & 78.5 & 12.5 & 32 & 113 & 11.8 & 18 & 20.1 & $-34.50[-41.46,-27.54]$ & & & & \\
\hline Zheng and Wang 2009 & 77.9 & 12 & 30 & 100.9 & 13.8 & 30 & 20.2 & $-23.00[-29.54,-16.46]$ & & & & \\
\hline Subtotal $(95 \% \mathrm{CI})$ & & & 96 & & & 82 & 60.0 & $-23.47[-35.39,-11.55]$ & & & & \\
\hline \multicolumn{13}{|c|}{$\begin{array}{l}\text { Heterogeneity: } \mathrm{Tau}^{2}=93.59 ; \mathrm{Chi}^{2}=13.75, \mathrm{df}=2(P=0.001) ; I^{2}=85 \% \\
\text { Test for overall effect: } Z=3.86(P=0.0001)\end{array}$} \\
\hline \multicolumn{13}{|l|}{ 2.2.2 AMI } \\
\hline Zhang et al. 2012 & 56.89 & 2.35 & 30 & 123.19 & 4.27 & 30 & 20.4 & $-66.30[-68.04,-64.56]$ & 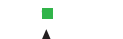 & & & \\
\hline Subtotal $(95 \% \mathrm{CI})$ & & & 30 & & & 30 & 20.4 & $-66.30[-68.04,-64.56]$ & $\downarrow$ & & & \\
\hline \multicolumn{13}{|c|}{ Heterogeneity: Not applicable } \\
\hline \multicolumn{13}{|c|}{ Test for overall effect: $Z=74.51(P<0.00001)$} \\
\hline \multicolumn{13}{|l|}{ 2.2.3 $\mathrm{AMI}+\mathrm{PCI}$} \\
\hline Wang 2017 & 116.23 & 32.79 & 53 & 134.67 & 30.81 & 53 & 19.5 & $-18.44[-30.55,-6.33]$ & & & & \\
\hline Subtotal $(95 \% \mathrm{CI})$ & & & 53 & & & 53 & 19.5 & $-18.44[-30.55,-6.33]$ & & & & \\
\hline \multicolumn{13}{|c|}{ Heterogeneity: Not applicable } \\
\hline \multicolumn{13}{|c|}{ Test for overall effect: $Z=2.98(P=0.003)$} \\
\hline Total (95\% CI) & & & 179 & & & 165 & 100.0 & $-30.93[-56.59,-5.27]$ & & & & \\
\hline \multicolumn{9}{|c|}{$\begin{array}{l}\text { Heterogeneity: } \mathrm{Tau}^{2}=838.64 ; \mathrm{Chi}^{2}=348.20, \mathrm{df}=4(P<0.00001) ; I^{2}=99 \% \\
\text { Test for overall effect: } \mathrm{Z}=2.36(\mathrm{P}=0.02)\end{array}$} & -50 & -25 & 25 & 50 \\
\hline \multicolumn{9}{|c|}{ Test for subgroup differences: $\mathrm{Chi}^{2}=105.13, \mathrm{df}=2(P<0.00001), I^{2}=98.1 \%$} & Favours (ex & erimental) & Favours & control) \\
\hline
\end{tabular}

FIgURE 6: The serum ET-1 levels of the included studies.

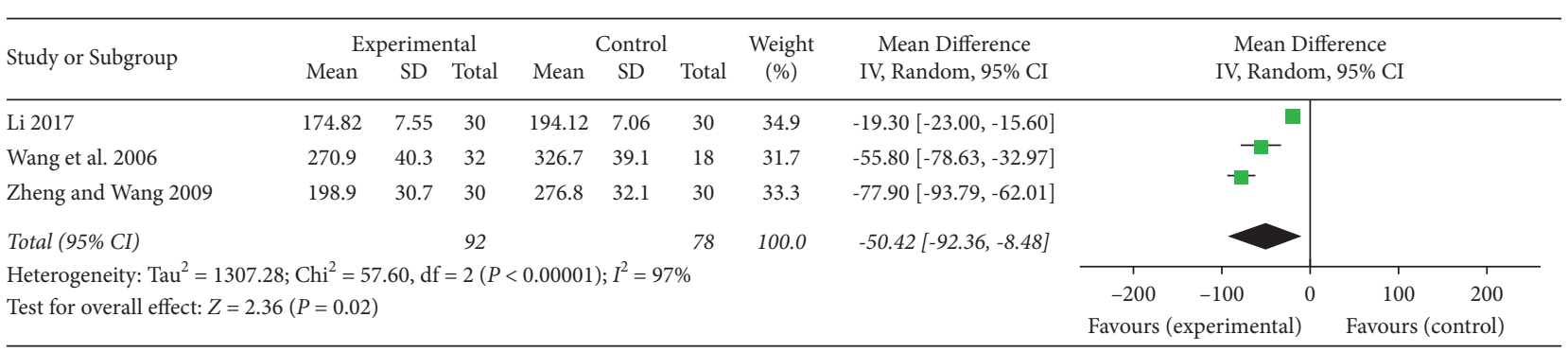

FIGURE 7: Assessment of the serum levels of ICAM-1 in the included studies.

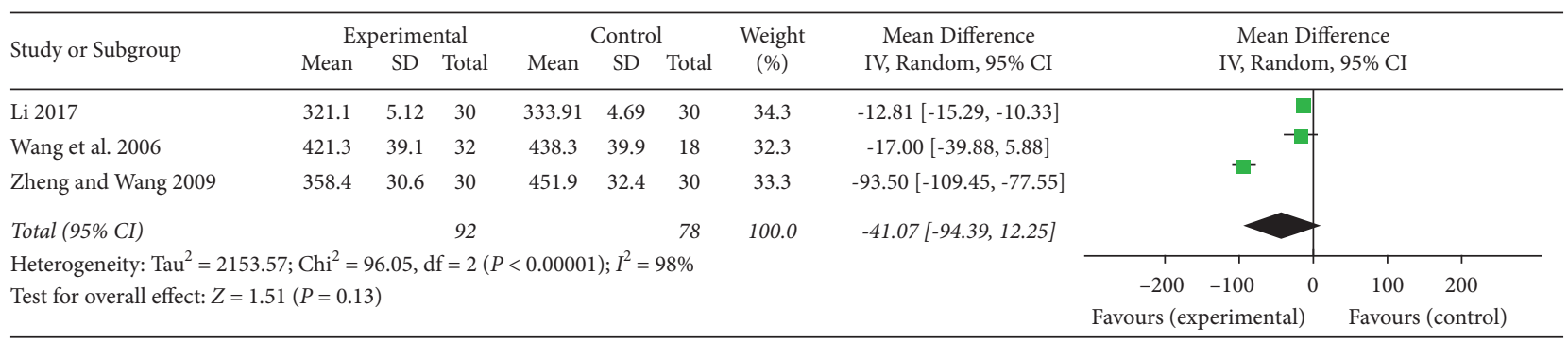

FIGURE 8: Assessment of the serum levels of VCAM-1 in the included studies.

and the RT groups. The results indicated that the XFZYD plus RT group performed better than the RT group alone $(0.099 \pm 0.019$ vs. $0.106 \pm 0.038, P<0.05)$.

3.4.6. ADRs. Two studies $[24,26]$ on UA reported ADRs in the treatment or control groups. One study [24] reported three mild diarrhea cases in the XFZYD plus RT group and two sinus bradycardia cases in the RT group. The symptoms disappeared following simple symptomatic treatments or the absence of therapies. Another study [26] reported two cases of elevated aminotransferase levels in the control group, whereas no ADRs were noted in the treatment group.

\section{Discussion}

In the present review, 16 studies of ACS were included, of which eight studies reported UA cases, three AMI, three AMI with PCI, one STEMI with PCI, and one NSTE-ACS (NSTEMI + UA). Among these studies, the combination of 


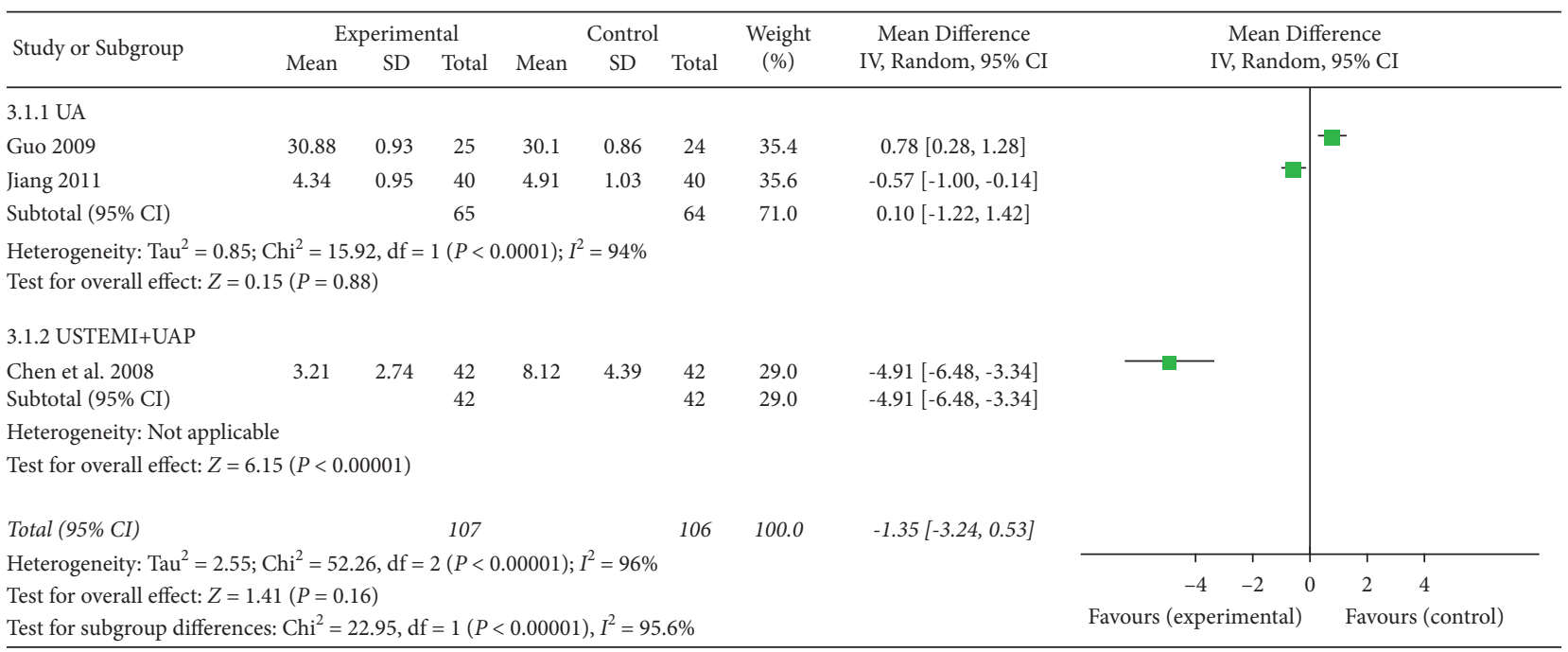

FIGURE 9: The serum CRP levels of the included studies.

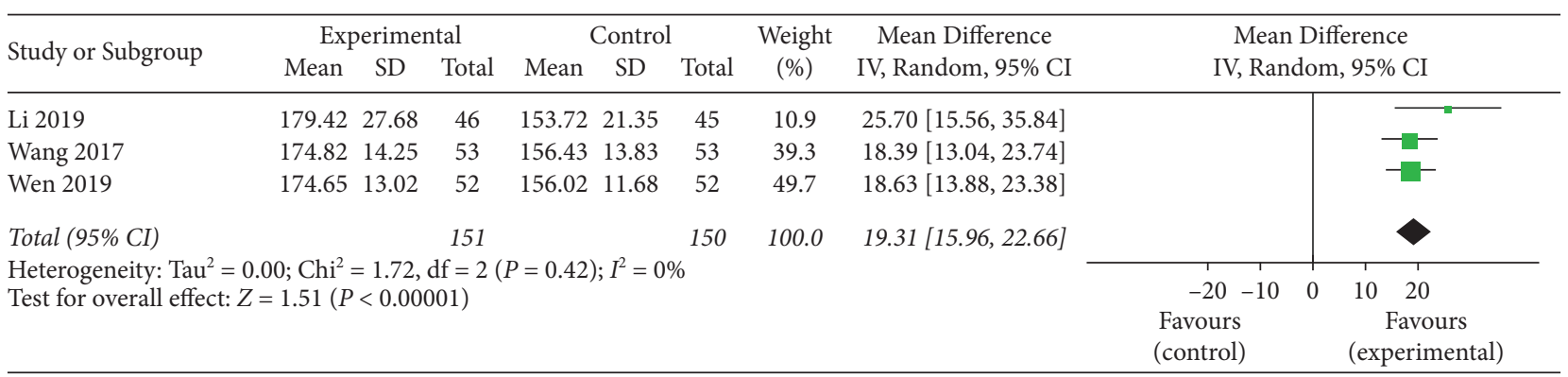

FIgURE 10: The serum SOD levels of the included studies.

XFZYD with RT exhibited the potential to improve cardiac and endothelial functions in ACS. The possible mechanisms of the effectiveness of this decoction are discussed below.

LVEF is positively related to the contractility of the myocardium; LVEDD and LVESD represent the diastolic and systolic functions of the left ventricle, respectively [36]. BNP is a quantitative marker of heart failure; CK-MB and cTnI are two sensitive indicators of myocardial damage [37]. The echocardiography results indicated the improvement of cardiac function, and XFZYD aided the amelioration of the levels of LVEF, LVEDD, and LVESD. In addition to these functions, XFZYD has been shown to decrease the blood levels of BNP and the myocardial enzymes (CK-MB and cTnI), representing cardioprotective effects. The cardioprotective function of XFZYD has been verified in various experimental studies. In the rat model of myocardial ischemia-reperfusion injury (MI/RI), XFZYD protected the myocardial ultrastructure [38]. Pretreatment with XFZYD demonstrated protective effects in the myocardial tissues of LPS-induced septic rats by inhibiting cardiomyocyte apoptosis and oxidative stress [39]. XFZYD demonstrated inhibition of myocardial apoptosis by increasing the expression of SIRT1 and inhibiting the expression levels of its downstream proteins $\mathrm{p} 53$ and NF- $\kappa \mathrm{B}$ in a model of $\mathrm{H} 9 \mathrm{c} 2$ rat myocardial cells with oxygen-glucose deprivation [40]. XFZYD was also shown to protect myocardial ischemia rats via the SIRT1-mediated signal transduction pathway [41]. The main components of XFZYD exhibited profound cardioprotective effects [10]. For example, hydroxysafflor yellow A reduced MI/RI injury, suppressed calcium overload in cardiomyocytes, and prevented the induction of their apoptosis [42]. Moreover, chlorogenic acid inhibited activation of the NF- $\kappa \mathrm{B}$ and JNK pathways in cardiomyocytes [43].

Endothelial dysfunction is accompanied by the rupture of vulnerable plaques and leads to platelet aggregation and leukocyte adherence [4]. The prominent vasoactive substance NO, released by the endothelium, helps mediate the vasodilation as well as regulates adhesion of leukocytes. NO can be regarded as a protector of cardiovascular endothelial function and vascular inflammation [44]. Endothelial function is also measured by the decreased ET-1 production, which is characterized as a vasoconstrictor [44, 45]. ICAM-1 and VCAM-1 are adhesion molecules. Their expression levels are increased as a result of facilitating leukocyte adhesion and transmigration inside the endothelium, which lead to further inflammatory expansion [46]. Serum CRP levels are also widely regarded as an indicator of inflammation. According to the results, XFZYD can significantly 


\begin{tabular}{|c|c|c|c|c|c|c|c|c|c|c|c|c|}
\hline \multirow{3}{*}{$\begin{array}{l}\text { Study or Subgroup } \\
\text { Li } 2019\end{array}$} & \multicolumn{3}{|c|}{ Experimental } & \multicolumn{3}{|c|}{ Control } & \multirow{2}{*}{$\begin{array}{l}\text { Weight } \\
(\%)\end{array}$} & \multirow{2}{*}{$\begin{array}{c}\text { Mean Difference } \\
\text { IV, Random, 95\% CI }\end{array}$} & \multirow{2}{*}{\multicolumn{4}{|c|}{$\begin{array}{c}\text { Mean Difference } \\
\text { IV, Random, 95\% CI }\end{array}$}} \\
\hline & Mean & SD & Total & Mean & SD & Total & & & & & & \\
\hline & 3.21 & 0.56 & 46 & 4.79 & 0.92 & 45 & 81.9 & $-1.58[-1.89,-1.27]$ & & & & \\
\hline Wang 2017 & 3.14 & 2.83 & 53 & 4.93 & 2.91 & 53 & 6.8 & $-1.79[-2.88,-0.70]$ & & & & \\
\hline Wen 2019 & 3.1 & 1.89 & 52 & 4.83 & 2.46 & 52 & 11.3 & $-1.73[-2.57,0.89]$ & & & & \\
\hline Total (95\% CI) & & & 151 & & & 150 & 100.0 & $-1.61[-1.90,-1.33]$ & & $\Delta$ & & \\
\hline \multicolumn{9}{|c|}{ Heterogeneity: $\mathrm{Tau}^{2}=0.00 ; \mathrm{Chi}^{2}=0.22, \mathrm{df}=2(P=0.90) ; I^{2}=0 \%$} & -4 & -2 & $\begin{array}{l}1 \\
2\end{array}$ & 4 \\
\hline \multicolumn{9}{|c|}{ Test for overall effect: $Z=11.12(P<0.00001)$} & Favours $(e$ & erimental) & \multicolumn{2}{|c|}{ Favours (control) } \\
\hline
\end{tabular}

FIgURE 11: The serum MDA levels of the included studies.

\begin{tabular}{|c|c|c|c|c|c|c|c|c|c|c|}
\hline \multirow{3}{*}{$\begin{array}{l}\text { Study or Subgroup } \\
4.1 .1 \mathrm{UA}\end{array}$} & \multicolumn{3}{|c|}{ Experimental } & \multicolumn{3}{|c|}{ Control } & \multirow{2}{*}{$\begin{array}{l}\text { Weight } \\
(\%)\end{array}$} & \multirow{2}{*}{$\begin{array}{l}\text { Mean Difference } \\
\text { IV, Random, 95\% CI }\end{array}$} & \multirow{2}{*}{\multicolumn{2}{|c|}{$\begin{array}{l}\text { Mean Difference } \\
\text { IV, Random, } 95 \% \text { CI }\end{array}$}} \\
\hline & Mean & $\mathrm{SD}$ & Total & Mean & SD & Total & & & & \\
\hline & & & & & & & & & & \\
\hline Guo 2009 & 275 & 63 & 25 & 284 & 62 & 24 & 19.7 & $-9.00[-44.00,26.00]$ & - & \\
\hline Lu 2020 & 75.58 & 6.42 & 43 & 122.78 & 8.43 & 40 & 40.0 & $-47.20[-50.44,-43.96]$ & & \\
\hline Subtotal (95\% CI) & & & 68 & & & 64 & 59.7 & $-32.24[-68.78,4.31]$ & & \\
\hline \multirow{2}{*}{\multicolumn{11}{|c|}{$\begin{array}{l}\text { Heterogeneity: } \mathrm{Tau}^{2}=568.79 ; \mathrm{Chi}^{2}=4.54, \mathrm{df}=1(P=0.03) ; I^{2}=78 \% \\
\text { Test for overall effect: } Z=1.73(P=0.008)\end{array}$}} \\
\hline & & & & & & & & & & \\
\hline \multicolumn{11}{|l|}{ 4.1.2 AMI } \\
\hline Liu et al. 2013 & 76.89 & 2.35 & 30 & 148.33 & 2.28 & 30 & 40.3 & $-71.44[-72.61,-70.27]$ & $\square$ & \\
\hline Subtotal $(95 \% \mathrm{CI})$ & & & 30 & & & 30 & 40.3 & $-71.44[-72.61,-70.27]$ & 1 & \\
\hline \multicolumn{11}{|c|}{ Heterogeneity: Not applicable } \\
\hline \multicolumn{11}{|c|}{ Test for overall effect: $Z=119.51(P<0.00001)$} \\
\hline Total (95\% CI) & & & 98 & & & 94 & 100.0 & $-49.43[-71.18,-27.68]$ & & \\
\hline \multicolumn{9}{|c|}{ Heterogeneity: $\mathrm{Tau}^{2}=305.27 ; \mathrm{Chi}^{2}=201.14, \mathrm{df}=2(P<0.00001) ; I^{2}=99 \%$} & -100 & 100 \\
\hline \multicolumn{9}{|c|}{ Test for overall effect: $Z=4.45(P<0.00001)$} & Favours (experimental) & Favours (control) \\
\hline
\end{tabular}

FIgURE 12: The blood levels of BNP in the included studies.

\begin{tabular}{|c|c|c|c|c|c|c|c|c|c|c|c|c|}
\hline \multirow{3}{*}{$\begin{array}{l}\text { Study or Subgroup } \\
5.1 .1 \mathrm{AMI}+\mathrm{PCI}\end{array}$} & \multicolumn{3}{|c|}{ Experimental } & \multicolumn{3}{|c|}{ Control } & \multirow{2}{*}{$\begin{array}{l}\text { Weight } \\
(\%)\end{array}$} & \multirow{2}{*}{$\begin{array}{l}\text { Mean Difference } \\
\text { IV, Random, 95\% CI }\end{array}$} & \multirow{2}{*}{\multicolumn{4}{|c|}{$\begin{array}{l}\text { Mean Difference } \\
\text { IV, Random, 95\% CI }\end{array}$}} \\
\hline & Mean & $\mathrm{SD}$ & Total & Mean & $\mathrm{SD}$ & Total & & & & & & \\
\hline & & & & & & & & & & & & \\
\hline Wang 2017 & 29.82 & 5.37 & 53 & 42.71 & 7.14 & 53 & 24.3 & $-12.89[-15.30,-10.48]$ & $\longrightarrow$ & & & \\
\hline Wen 2019 & 28.42 & 7.51 & 52 & 39.64 & 8.11 & 52 & 23.1 & $-11.22[-14.22,-8.22]$ & & & & \\
\hline Subtotal (95\% CI) & & & 105 & & & 105 & 47.5 & $-12.24[-14.12,-10.36]$ & & & & \\
\hline \multirow{2}{*}{\multicolumn{13}{|c|}{$\begin{array}{l}\text { Heterogeneity: } \mathrm{Tau}^{2}=0.00 ; \mathrm{Chi}^{2}=0.72, \mathrm{df}=1(P=0.40) ; I^{2}=0 \% \\
\text { Test for overall effect: } Z=12.77(P<0.00001)\end{array}$}} \\
\hline & & & & & & & & & & & & \\
\hline \multicolumn{13}{|l|}{$5.1 .2 \mathrm{UA}$} \\
\hline Li 2017 & 48.14 & 2.07 & 30 & 53.46 & 1.944 & 30 & 26.3 & $-5.32[-6.34,-4.30]$ & & - & & \\
\hline Subtotal (95\% CI) & & & 30 & & & 30 & 26.3 & $-5.32[-6.34,-4.30]$ & & $\checkmark$ & & \\
\hline \multicolumn{13}{|c|}{ Heterogeneity: Not applicable } \\
\hline \multicolumn{13}{|c|}{ Test for overall effect: $Z=10.27(P<0.00001)$} \\
\hline \multicolumn{13}{|l|}{ 5.1.3 STEMI+PCI } \\
\hline Li 2019 & 30.06 & 1.73 & 46 & 41.3 & 3.15 & 45 & 26.3 & $-11.24[-12.29,-10.19]$ & & & & \\
\hline Subtotal $(95 \% \mathrm{CI})$ & & & 46 & & & 45 & 26.3 & $-11.24[-12.29,-10.19]$ & & & & \\
\hline \multicolumn{13}{|c|}{ Heterogeneity: Not applicable } \\
\hline \multicolumn{13}{|c|}{ Test for overall effect: $Z=21.03(P<0.00001)$} \\
\hline Total $(95 \%$ CI) & & & 181 & & & 180 & 100.0 & $-10.08[-14.01,-6.15]$ & & & & \\
\hline \multicolumn{9}{|c|}{ Heterogeneity: $\mathrm{Tau}^{2}=15.01 ; \mathrm{Chi}^{2}=79.53, \mathrm{df}=3(P<0.00001) ; I^{2}=96 \%$} & & $\begin{array}{ll}-5 & 0\end{array}$ & 5 & 10 \\
\hline \multicolumn{9}{|c|}{ Test for overall effect: $Z=5.03(P<0.00001)$} & $\begin{array}{c}-10 \\
\text { Favours (exper }\end{array}$ & ${ }^{-5} 0$ & $\begin{array}{c}5 \\
\text { Favour }\end{array}$ & s (control) \\
\hline
\end{tabular}

FIgUre 13: The blood levels of CK-MB in the included studies. 
increase the serum levels of NO, and reduce serum ET- 1 and ICAM-1 levels, indicating the protective effects on vascular endothelial function. However, XFZYD may not decrease serum VCAM-1 and CRP levels, which may be associated with the sample size of the included study. Therefore, additional research studies are required in the future. The systemic pharmacology of XFZYD in the prevention of atherosclerotic cardiovascular disease (ASCVD) has shown that the mechanism of XFZYD is mainly reflected in the protection of vascular endothelium, prevention of oxidative stress, and inhibition of inflammation; the effective component quercetin was also shown to protect injured endothelial cells and reduce the endothelial inflammatory response (ICAM-1, VCAM-1, and TNF- $\alpha$ ) induced by LPS in vitro [47]. XFZYD has been shown to protect from ischemic necrosis, induce the migration of endothelial progenitor cells, and promote angiogenesis by improving the serum levels of NO [48]. Following XFZYD treatment, the serum levels of ET-1 were decreased and NO levels were released in MI/RI swine [49]. XFZYD can restrain inflammation, platelet aggregation, and help protect reendothelialization after PCI. The indicators reported both from clinical and experimental studies that have shown the efficacy of XFZYD in ASCVD.

SOD is an antioxidant metal enzyme that can catalyze the disproportionation of superoxide anion radicals to produce oxygen and hydrogen peroxide [50]. It plays a vital role in maintaining the balance required (pro-oxidants/ antioxidants) to prevent the induction of oxidative stress in the body [50]. In several organisms, free radicals bind to lipids to induce their peroxidation, which results in the production of MDA. The latter can reflect the degree of lipid peroxidation in the body and indirectly reflect the degree of cell damage [51]. Higher SOD and lower MDA levels play inhibitory roles against the development of ACS. The results indicated that XFZYD could upregulate the serum levels of SOD and downregulate the serum levels of MDA, reducing serum oxidative stress levels and improving the function of the endothelial microenvironment. Previous studies have also shown that XFZYD plays an antioxidant role by reducing serum MDA levels and increasing serum SOD levels in CHD patients undergoing PCI surgery [52].

Endothelial dysfunction, oxidative stress, abnormal vasoconstriction, and dilation are crucial in the pathogenesis of atherosclerosis and ACS [53, 54]. XFZYD can improve cardiac function by increasing blood supply to myocardium and can ameliorate coronary microcirculation by improving endothelial function. Future studies can focus on these mechanisms for ACS to uncover more potential drug targets and long-term effects of this formula. Based on these results, the practical applications of XFZYD with conventional therapy can be used in ACS patients as soon as possible.

The limitations of this systematic review can be summarized in the following three aspects: First of all, the number of studies included in the meta-analysis was considerably small, and only six studies were involved in the meta-analysis of the primary outcome (LVEF), which could not be used for analyzing the publication bias. Moreover, the heterogeneity among all the ACS subtypes was too high in the meta-analysis. Therefore, subgroup analysis was conducted according to the ACS subtypes of STEMI, USTEMI, and UA, with or without PCI. Lower heterogeneity was detected, whereas a smaller number of studies were involved in the subgroup analysis, which may lead to unstable results. Finally, almost all the included studies were published in Chinese, while only one was published in English, and none of them reported the allocation concealment and blinding method, which augmented the risk of bias in RCTs.

\section{Conclusions}

In summary, the present analysis demonstrated that XFZYD can be used as a representative Chinese prescription, which may possess significant clinical applications for improving cardiac and endothelial functions and the LVEF, LVEDD, LVESD, NO, ET-1, and ICAM-1 of ACS patients when combined with RT. Moreover, it may also ameliorate the levels of oxidative stress (SOD and MDA), BNP, CK-MB, and cTnI. No serious ADRs were noted. However, XFZYD may not improve the blood levels of VCAM-1 and CRP. On the basis of these results, we prefer to confirm the amelioration of cardiac and endothelial functions of XFZYD in ACS. However, considering the mediocre methodological quality and a small number of included studies, it is deduced that multicenter, large-scale, and strictly designed trials are required to confirm these findings. This systematic review has provided evidence for the clinical efficacy of XFZYD combined with RT in treating patients with ACS.

\section{Abbreviations}

ACS: $\quad$ Acute coronary syndrome

ADRs: Adverse drug reactions

AMI: Actue myocardial infarction

ASCVD: Atherosclerotic cardiovascular disease

BNP: $\quad$ Brain natriuretic peptide

CK-MB: Creatine kinase-MB

CHD: $\quad$ Coronary heart disease

CI: $\quad$ Confidence interval

CRP: C-reactive protein

cTnI: Cardiac troponin I

ECG: Electrocardiogram

ET-1: Endothelin-1

ICAM-1: Intercellular adhesion molecule-1

ICD-10: International classification of diseases10th revision

LVEF: Left ventricular ejection fraction

LVEDD: Left ventricular end-diastolic diameter

LVESD: Left ventricular end-systolic diameter

MDA: Malondialdehyde

MI: $\quad$ Myocardial infarction

MI/RI: $\quad$ Myocardial ischemia-reperfusion injury

NO: $\quad$ Nitric oxide

NSTEMI: Non-ST-segment elevation myocardial infarction

PCI: Percutaneous coronary intervention

RCTs: Randomized controlled trials

RT: $\quad$ Routine treatment

SMD: $\quad$ Standardized mean difference 
SOD: $\quad$ Superoxide dismutase

STEMI: ST-segment elevation myocardial infarction

TCM: Traditional Chinese medicine

UA: Unstable angina

VCAM- Vascular cell adhesion molecule-1

$1:$

WMD: Weighted mean difference

XFZYD: Xue-Fu-Zhu-Yu decoction.

\section{Data Availability}

All the data generated or analyzed during this study are included in this published article and its additional files.

\section{Disclosure}

Shiqi Chen, Xiaoxiao $\mathrm{Wu}$, and Tong Li are cofirst authors. Mingjing Zhao and Yahong Wang are the corresponding authors.

\section{Conflicts of Interest}

The authors declare that there are no conflicts of interest regarding the publication of this article.

\section{Authors' Contributions}

YHW and MJZ designed the research and supervised the whole process. SQC and TL conducted the literature searching and selection. XXW and WTC extracted and analyzed the outcomes. XWH and YL assessed the risk of bias. SQC drafted the manuscript with the help of BFW and YT. MJZ and YHW detected any mistakes in the entire process. All authors have approved the final manuscript for submission.

\section{Acknowledgments}

This work was supported by the National Natural Science Foundation Project of China (81774127) and the 2020 Science and Technology Innovation Project of Dongzhimen Hospital (DZMKJCX-2020-012).

\section{Supplementary Materials}

Table S1: other characteristics of the included studies. (Supplementary Materials)

\section{References}

[1] T. K. M. Wang, C. Grey, Y. Jiang, R. T. Jackson, and A. J. Kerr, "Nationwide trends in acute coronary syndrome by subtype in New Zealand 2006-2016," Heart (British Cardiac Society), vol. 106, no. 3, pp. 221-227, 2020.

[2] E. J. Benjamin, M. J. Blaha, S. E. Chiuve et al., "Heart disease and stroke statistics-2017 update: a report from the American heart association," Circulation, vol. 135, no. 10, pp. e146-e603, 2017.

[3] J. C. Trost and R. A. Lange, "Treatment of acute coronary syndrome: Part 1: non-ST-segment acute coronary syndrome," Critical Care Medicine, vol. 39, no. 10, pp. 2346-2353, 2011.

[4] F. Crea and P. Libby, "Acute coronary syndromes: the way forward from mechanisms to precision treatment," Circulation, vol. 136, no. 12, pp. 1155-1166, 2017.

[5] L. Esposito, F. P. Cancro, A. Silverio et al., "COVID-19 and acute coronary syndromes: from pathophysiology to clinical perspectives," Oxidative Medicine and Cellular Longevity, vol. 2021, Article ID 4936571, 13 pages, 2021.

[6] K. P. Kline, C. R. Conti, and D. E. Winchester, "Historical perspective and contemporary management of acute coronary syndromes: from MONA to THROMBINS2," Postgraduate Medicine, vol. 127, no. 8, pp. 855-862, 2015.

[7] P. G. Steg, K. Huber, F. Andreotti et al., "Bleeding in acute coronary syndromes and percutaneous coronary interventions: position paper by the working group on thrombosis of the European society of cardiology," European Heart Journal, vol. 32, no. 15, pp. 1854-1864, 2011.

[8] K. K. R. Mangalpally and N. S. Kleiman, "The safety of clopidogrel," Expert Opinion on Drug Safety, vol. 10, no. 1, pp. 85-95, 2011.

[9] J. G. Córdoba-Soriano, M. Corbí-Pascual, I. López-Neyra et al., "Early aspirin desensitization in unstable patients with acute coronary syndrome: short and long-term efficacy and safety," European Heart Journal: Acute Cardiovascular Care, vol. 5, no. 7, pp. 41-50, 2016.

[10] C. Fu, Z. Xia, Y. Liu et al., "Qualitative analysis of major constituents from Xue Fu Zhu Yu decoction using ultra high performance liquid chromatography with hybrid ion trap time-of-flight mass spectrometry," Journal of Separation Science, vol. 39, no. 17, pp. 3457-3468, 2016.

[11] X.-J. Xiong, Z. Wang, and J. Wang, "Innovative strategy in treating angina pectoris with Chinese patent medicines by promoting blood circulation and removing blood stasis: experience from combination therapy in Chinese medicine," Current Vascular Pharmacology, vol. 13, no. 4, pp. 540-553, 2015.

[12] J. Wang, X. Yang, F. Chu et al., "The effects of Xuefu Zhuyu and shengmai on the evolution of syndromes and inflammatory markers in patients with unstable angina pectoris after percutaneous coronary intervention: a randomised controlled clinical trial," Evidence-based Complementary and Alternative Medicine, vol. 2013, Article ID 896467, 9 pages, 2013.

[13] G. Z. Yi, Y. Q. Qiu, Y. Xiao, and L. X. Yuan, “The usefulness of Xuefu Zhuyu tang for patients with angina pectoris: a metaanalysis and systematic review," Evidence-Based Complementary and Alternative Medicine, vol. 2014, Article ID 521602, 11 pages, 2014.

[14] D. Wang, P. Wang, R. Zhang, and X. Xi, "Efficacy and safety of Xuefu Zhuyu decoction combined with Western medicine for angina pectoris in coronary heart disease: a protocol for systematic review and meta-analysis," Medicine (Baltimore), vol. 99, no. 50, Article ID e23195, 2020.

[15] F. Y. Chu, J. Wang, K. W. Yao, and Z. Z. Li, "Effect of Xuefu Zhuyu capsule on the symptoms and signs and health-related quality of life in the unstable angina patients with blood-stasis syndrome after percutaneous coronary intervention: a randomized controlled trial," Chinese Journal of Integrative Medicine, vol. 16, no. 5, pp. 399-405, 2010.

[16] P. T. O’Gara, F. G. Kushner, D. D. Ascheim et al., “2013 ACCF/AHA guideline for the management of ST-elevation myocardial infarction: a report of the american college of cardiology foundation/american heart association task force 
on practice guidelines," Journal of the American College of Cardiology, vol. 61, no. 4, pp. e78-e140, 2013.

[17] H. Jneid, J. L. Anderson, R. S. Wright et al., "2012 ACCF/AHA focused update of the guideline for the management of patients with unstable angina/non-ST-elevation myocardial infarction (updating the 2007 guideline and replacing the 2011 focused update): a report of the american college of cardiology foundation/american heart association task force on practice guidelines," Journal of the American College of Cardiology, vol. 60, no. 7, pp. 645-681, 2012.

[18] M. M. Mafham, E. Spata, R. Goldacre et al., "COVID-19 pandemic and admission rates for and management of acute coronary syndromes in England," The Lancet, vol. 396, no. 10248 , pp. $381-389,2020$.

[19] C. Andrade, "Mean difference, standardized mean difference (SMD), and their use in meta-analysis: as simple as it gets," Journal of Clinical Psychiatry, vol. 81, no. 5, 2020.

[20] X. H. Zu, "Observation on the effect of Xuefu Zhuyu decoction combined with double antiplatelet drugs after percutaneous coronary intervention in acute myocardial infarction," Journal of Practical Traditional Chinese Medicine, vol. 36, no. 01, pp. 49-50, 2020.

[21] C. J. Lu, "Effects of Xuefu Zhuyu decoction combined with amiodarone on unstable angina pectoris," Shenzhen Journal of Integrated Traditional Chinese and Western Medicine, vol. 30, no. 19, pp. 36-37, 2020.

[22] H. X. Wen, "Application of Xuefu Zhuyu decoction in myocardial infarction after percutaneous coronary intervention," Chinese Journal of Ethnomedicine and Ethnopharmacy, vol. 28, no. 05, pp. 97-99, 2019.

[23] G. W. Li, "Effects of Xuefu Zhuyu decoction on myocardial enzymes and cardiac function in patients with myocardial ischemia-reperfusion injury after acute myocardial infarction," Jounal of Medical Therapy and Practice, vol. 32, no. 23, pp. 3804-3805, 2019.

[24] P. Liu and L. Liu, "Effects of Xuefu Zhuyu granule combined with metoprolol on unstable angina pectoris in young and middle-aged people," Chinese Journal of Integrative Medicine on Cardio-/Cerebrovascuiar Disease, vol. 16, no. 19, pp. 2845-2847, 2018.

[25] N. Wang, "Effect of Xuefu Zhuyu decoction on myocardial reperfusion and cardiac function in patients with myocardial infarction after percutaneous coronary intervention," Modern Journal of Integrated Traditional Chinese and Western Medicine, vol. 26, no. 01, pp. 73-75, 2017.

[26] G. S. Li, "Effect of Xuefu Zhuyu decoction on adhesion molecules in patients with unstable angina pectoris," Neimenggu Traditional Chinese Medicine, vol. 36, no. 19, pp. 4-5, 2017.

[27] J. W. Wang, "Clinical effect analysis of Xuefu Zhuyu decoction on unstable angina pectoris," Contemporary Medical Symposium, vol. 14, no. 19, pp. 60-61, 2016.

[28] Y. F. Liu, X. H. Han, Y. H. Zhang, M. Chen, H. F. Zhou, and J. Y. Liu, "Xuefu Zhuyu decoction for acute myocardial infarction and its effects on erythrocyte immune function and B-type natriuretic peptide," Journal of Clinical Research, vol. 30, no. 10, pp. 2070-2071, 2013.

[29] Y. H. Zhang, Y. F. Liu, and M. Chen, "Effect of Xuefu Zhuyu decoction on acute myocardial infarction and endothelin of erythrocyte immune function," Chinese Journal of Practical Internal Medicine, vol. 32, no. S2, pp. 26-27, 2012.

[30] W. J. Jiang, "Clinical observation of Xuefu Zhuyu capsule in treating unstable angina pectoris," Journal of New Chinese Medicine, vol. 43, no. 01, pp. 15-17, 2011.
[31] G. L. Zheng and S. H. Wang, "Clinical effect and mechanism of Xuefu Zhuyu capsule in treating unstable Angina pectoris," Chinese Journal of Integrated Traditional and Western Medicine, vol. 29, no. 01, pp. 65-68, 2009.

[32] H. Guo, "Effects of Xuefu Zhuyu capsule on CRP and BNP in patients with unstable angina pectoris," Tianjin Journal of Traditional Chinese Medicine, vol. 26, no. 03, pp. 209-210, 2009.

[33] N. T. Chen, H. Chen, H. Y. Zhu, Q. Zhao, J. Liu, and D. F. Zhang, "Clinical study of Xuefu Zhuyu decoction on 42 cases of acute coronary syndrome with non-ST segment elevation," Journal of Hubei College of Traditional Chinese Medicine, vol. 10, no. 04, pp. 44-46, 2008.

[34] B. X. Wang, X. M. Dong, A. M. Guo, and J. Zhang, "Effects of Xuefu Zhuyu decoction on functions of vascular endothelium in patients with unstable angina pectoris," Journal of Chinese Integrative Medicine, vol. 4, no. 03, pp. 256-259, 2006.

[35] Y. P. Tang, Y. Liu, and P. Liang, "Clinical study on preventing and treating left ventricle remodeling after acute myocardial infarction with integrative Chinese and western medicine," Chinese Journal of Integrative Medicine, vol. 10, no. 1, pp. 25-28, 2004.

[36] S. Y. Yu, B. Dong, Z. F. Fang, X. Q. Hu, L. Tang, and S. H. Zhou, "Knockdown of lncRNA AK139328 alleviates myocardial ischaemia/reperfusion injury in diabetic mice via modulating miR-204-3p and inhibiting autophagy," Journal of Cellular and Molecular Medicine, vol. 22, no. 10, pp. 48864898, 2018.

[37] J. Xie, L. Zhang, X. Fan, X. Dong, Z. Zhang, and W. Fan, "MicroRNA-146a improves sepsis-induced cardiomyopathy by regulating the TLR-4/NF- $\kappa \mathrm{B}$ signaling pathway," Experimental and Therapeutic Medicine, vol. 18, no. 1, pp. 779-785, 2019.

[38] D. Tang, Z. Liu, H. Zhang, M. Sun, and Y. Sui, "Protective effects of Xuefu Zhuyu decoction on myocardium ischemia reperfusion injury in rats," Zhongguo Zhong Yao Za Zhi, vol. 35, no. 22, pp. 3077-3079, 2010.

[39] F. Meng, H. Lai, Z. Luo et al., "Effect of xuefu zhuyu decoction pretreatment on myocardium in sepsis rats," Evidence-Based Complementary and Alternative Medicine, vol. 2018, Article ID 2939307, 10 pages, 2018.

[40] M. Q. Chen, K. W. Yao, Z. J. Liu, X. X. Feng, and Y. Xiao, "Xuefu zhuyu oral liquid prevents apoptosis of ischemic myocardium cells in rats by regulating SIRT1 and its pathwayrelated genes," Chinese Journal of Integrative Medicine, vol. 26, no. 6, pp. 442-447, 2020.

[41] F. Teng, G. Li, Z. Liu, L. Zhang, and K. Yao, "The comparative study on expression of SIRT1 signal transduction by xuefuzhuyu capsule," Evidence-Based Complementary and Alternative Medicine, vol. 2014, Article ID 537014, 8 pages, 2014.

[42] J. Ye, R. Wang, M. Wang et al., "Hydroxysafflor yellow A ameliorates myocardial ischemia/reperfusion injury by suppressing calcium overload and apoptosis," Oxidative Medicine and Cellular Longevity, vol. 2021, Article ID 6643615, 14 pages, 2021.

[43] L. Tian, C. P. Su, Q. Wang et al., "Chlorogenic acid: a potent molecule that protects cardiomyocytes from TNF- $\alpha$-induced injury via inhibiting NF- $\kappa \mathrm{B}$ and JNK signals," Journal of Cellular and Molecular Medicine, vol. 23, no. 7, pp. 4666-4678, 2019.

[44] O. Levy-Ontman, M. Huleihel, R. Hamias, T. Wolak, and E. Paran, "An anti-inflammatory effect of red microalga polysaccharides in coronary artery endothelial cells," Atherosclerosis, vol. 264, pp. 11-18, 2017. 
[45] B. Simic, M. Hermann, S. G. Shaw et al., "Torcetrapib impairs endothelial function in hypertension," European Heart Journal, vol. 33, no. 13, pp. 1615-1624, 2012.

[46] A. Armoza, Y. Haim, A. Basiri, T. Wolak, and E. Paran, "Tomato extract and the carotenoids lycopene and lutein improve endothelial function and attenuate inflammatory NF- $\kappa$ B signaling in endothelial cells," Journal of Hypertension, vol. 31, no. 3, pp. 521-529, 2013.

[47] B. Liang, Y. Xiang, X. Zhang et al., "Systematic pharmacology and GEO database mining revealed the therapeutic mechanism of Xuefu Zhuyu decoration for atherosclerosis cardiovascular disease," Frontiers In Cardiovascular Medicine, vol. 7, Article ID 592201, 2020.

[48] D. Gao, Y. H. Jiao, and Y. M. Wu, "Experimental study of Xuefu Zhuyu decoction induced participation of endothelial progenitor cells in the angiogenesis of the ischemic region," Zhongguo Zhong Xi Yi Jie He Za Zhi, vol. 32, no. 2, pp. 224-228, 2012.

[49] X. Hou, B. L. Li, L. Zhao, S. D. Huang, Z. Y. Xu, and G. X. Zhang, "Effects of Xuefu Zhuyu capsule on endothelin-1 release in myocardium and vascular endothelium and nitric oxide/nitric oxide synthase system of swines after acute myocardial infarction and reperfusion," Zhong Xi Yi Jie He Xue Bao, vol. 6, no. 4, pp. 381-386, 2008.

[50] B. Mansuroğlu, S. Derman, A. Yaba, and K. Kızılbey, "Protective effect of chemically modified SOD on lipid peroxidation and antioxidant status in diabetic rats," International Journal of Biological Macromolecules, vol. 72, pp. 79-87, 2015.

[51] S. Raghavan, G. Subramaniyam, and N. Shanmugam, "Proinflammatory effects of malondialdehyde in lymphocytes," Journal of Leukocyte Biology, vol. 92, no. 5, pp. 1055-1067, 2012.

[52] J. Zhao, H. Liu, B. Xu et al., "The role of xuefu zhuyu decoction in prevention of contrast-induced nephropathy after percutaneous coronary intervention," Evidence-Based Complementary and Alternative Medicine, vol. 2020, Article ID 5419016, 7 pages, 2020.

[53] V. Lubrano, A. Pingitore, I. Traghella et al., "Emerging biomarkers of oxidative stress in acute and stable coronary artery disease: levels and determinants," Antioxidants (Basel, Switzerland), vol. 8, no. 5, 2019.

[54] P. Libby, G. Pasterkamp, F. Crea, and I.-K. Jang, "Reassessing the mechanisms of acute coronary syndromes," Circulation Research, vol. 124, no. 1, pp. 150-160, 2019. 